\title{
Effect of Blending Ratio on Quality of Producer Gas From Co-Gasification of Wood and Coconut Residual
}

\author{
Muddasser Inayat ${ }^{1, *}$, and Shaharin A. Sulaiman ${ }^{1}$ \\ ${ }^{1}$ Department of Mechanical Engineering, Universiti Teknologi PETRONAS, 32610 Seri Iskandar, \\ Perak, Malaysia
}

\begin{abstract}
Biomass gasification often encounters the shortage of biomass supply for continuous operation. Co-gasification of different biomass materials is a promising solution that can address the shortage of biomass supply for the continuous gasification process. However, the effectiveness of co-gasification is not well understood. Furthermore, there is nearly no reported work of co-gasification of two or more biomass materials. In this study, two Malaysian local biomass materials, wood residual and coconut shells were co-gasified in a $33.6 \mathrm{~kW}$ thermal capacity downdraft gasifier to investigate the effect of blending ratio the on quality of the producer gas. The results show that producer gas composition increased as coconut shells proportion increased in blends of up to $60 \%$. A blend of 40:60 W/CS results in a synergetic effect as compared to discrete gasification of both feedstock. The maximum $\mathrm{H}_{2}$ and $\mathrm{CO}$ were obtained as; 11.46 vol.\% and 23.99 vol.\% respectively at 40:60 W/CS blending ratio. The results achieved from 40:60 $\mathrm{W} / \mathrm{CS}$ blend were $16.70 \%$ and $10.96 \%$ higher as compared to pure wood gasification for $\mathrm{H}_{2}$ and $\mathrm{CO}$ respectively. It is concluded that coconut shells can be utilized a substitute of wood residual in form of blends or as discrete feedstock for the continuous gasification process without the change in gasifier geometry.
\end{abstract}

\section{Introduction}

The world projected to face energy shortage and global environmental issues related to the emission of conventional fossil fuel. In the meantime, modern lifestyle utilizes a high amount of energy that comes from petroleum energy sources [1]. The utilization of biomass is considered a promising renewable energy source that could be a substitution of fossil fuels via gasification. Malaysia is bestowed with verities of biomass resources due to its tropical weather and its location near the equator. The main areas, which contribute to the streamline of the biomass energy supply, are forestry (30.56\%) and agricultural sector. In 2010, 12 million $\mathrm{m}^{3}$ of timber logs were produced from the Malaysian forest area [2]. The wood waste generated during the logging operation is 5.1 million $\mathrm{m}^{3}$ in form of stumps, branches, bark, tops, broken logs, defective logs and injured standing trees, all these are $43 \%$ of total

\footnotetext{
${ }^{*}$ Corresponding author: muddasser_engr@yahoo.com
} 
volume of the tree [3]. In addition, Malaysian agricultural crops contributed as; oil palm $(43.67 \%)$, rubber $(30.56 \%)$, rice $(12.68 \%)$, cocoa $(6.75 \%)$ and coconut $(6.34 \%)[4,5]$. Coconut is another industrial crop in Malaysia, which is the third biggest in plantation area size. In 2009, the total domestic coconut production was about 459,000 tons. From coconut processing, coconut husk (0.166 Mton), coconut shell (0.735 Mton), coconut frond (0.103 Mton) and coconut empty bunches $(0.022 \mathrm{Mton})$ are obtained as by-products. In terms of total energy supply, it contributed $6 \mathrm{PJ}\left(1 \times 10^{15}\right)$ in 2009 [2].

Although biomass can be gasified to mitigate the issues associated with fossil fuels depletion and emission [6, 7]. However, dependence on discrete biomass feedstock could be problematic for continuous gasification operation. The operation often encounters a problem of unsteady supply of feedstock throughout the year and can be affected by factors like drought and heavy rain. In additions, some biomass materials are available in limited quantity, not sufficient to support continuous biomass gasification. The pre-mentioned issues related to biomass supply can be mitigated by mixing of different biomass materials to ensure uninterrupted biomass gasification [8]. Therefore, the wood and coconut shells base lignocellulosic biomass materials are considered as a potential source of energy, which could be exploited by using a co-gasification process [2]. Recently, co-gasification of different biomass is the emerging interest of many researchers [9-19].

In this study, wood residual (W) and coconut shells (CS) co-gasified in downdraft gasifier to investigate the coconut shells as a wood substitute. Furthermore, the effect of blending ratio was investigated on producer gas quality. The quality of producer gas is described in terms of gas composition. The quality of producer gas is important to decide its final utilization for energy explication. The composition of producer gas consists of combustible gases, for instance; $\mathrm{CO}, \mathrm{H}_{2}$, and $\mathrm{CH}_{4}$ and non-combustible gases $\mathrm{CO}_{2}$ and $\mathrm{N}_{2}$ [20].

\section{Materials and methods}

\subsection{Experimental setup and procedure}

The wood residual and CS were the potential feedstock for the current study. Wood logs were collected from the landscape of the Universiti Teknologi PETRONAS, Malaysia during tree trimming activities. Coconut shells were obtained from local coconut market at Batu Gajah, Perak, Malaysia. Both feedstocks were chopped using a shredding machine at a timber factory, located at Ayer Tawar, Perak, Malaysia, and sieve it. Feedstocks were dried at $105^{\circ} \mathrm{C}$ for 24 hours using an electric oven as per ASTM E871-82 standard method [21]. The proximate analysis, ultimate analysis, and higher heating value (HHV) of feedstocks samples were performed as per ASTM E1755-01 in a STA 6000 TGA analyzer, ASTM D3176-09 in Leco CHNS-932 analyzer, and ASTM D4809-00 in Leco AC-350 automatic bomb calorimeter respectively, the results are shown in Table 1 [22-24]. A $33.6 \mathrm{~kW}$ (thermal) pilotscale batch feed downdraft gasification system designed and devolved by Guangul et al.,2012 [25] was used in this study as shown in Fig. 1. The system consisted of a gasifier, air blower, rotameter, Type-K thermocouples $\left(\mathrm{T}_{1}-\mathrm{T}_{7}\right)$, cyclone and gas filtering, gas cleaning and cooling, and gas analyzer.

As producer gas left the outlet of the gasifier, it passed through the cyclone where particulates in gas were removed. Next, it passed through a filter, which removed tar and moisture from producer gas. Producer gas was sampled after leaving the first stage of gas cooling and filtering system. For more cleaning and cooling of the sample, gas passed through a mechanical cooling and cleaning system. The cooling and cleaning system consisted of a gas cooler, pump, rotameter, $4 \mu \mathrm{m}$ ceramic filter, and gas flow control valve. The gas was cooled down to $5^{\circ} \mathrm{C}$ in the gas cooler and condensate was removed from the cooler using two 
integrated peristaltic pumps. Moisture free producer gas was pumped to the ceramic filter for further particulate removal. Clean and cool producer gas was pumped into an online analyzer through rotameter at control flow rate of $1.0 \mathrm{~L} / \mathrm{min}$. Emerson made X2GP-Stream $(\leq 1 \%)$ online gas analyzer used to measure the volumetric gas composition of producer gas. Gas analyzer displayed the concentration of four gases, namely $\mathrm{CO}, \mathrm{H}_{2}, \mathrm{CH}_{4}$ and $\mathrm{CO}_{2}$ on its $\mathrm{LCD}$ screen. Each experiment was repeated three times and average values are presented in results and discussion section.

\subsection{Data analysis method}

The average gas composition of $\mathrm{H}_{2}, \mathrm{CO}, \mathrm{CH}_{4}$, and $\mathrm{CO}_{2}$ was calculated by:

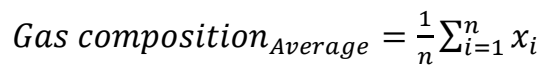

Where $n$ is the number of gas samples and $x_{i}$ is the concentration of any component of producer gas.

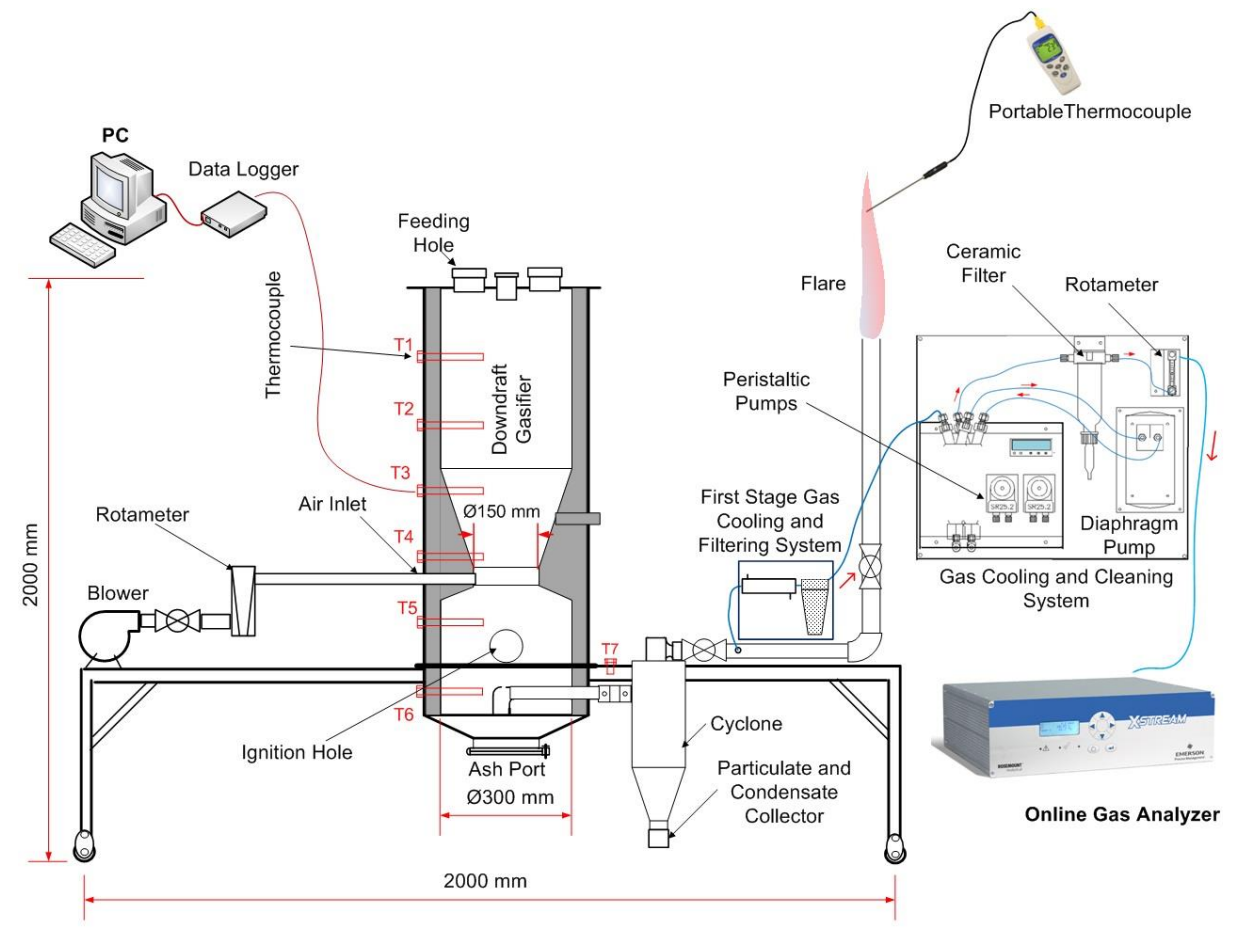

Fig. 1. Downdraft gasification system.

\section{Results and discussion}

Table 1. Characteristics of processed wood residual and coconut shells

\begin{tabular}{ccccccccccc}
\hline \multirow{2}{*}{ Biomass } & \multicolumn{4}{c}{ Ultimate Analysis (wt. \%) } & \multicolumn{4}{c}{ Proximate Analysis (wt. \%) } & HHV \\
\cline { 2 - 10 } & $\mathbf{C}$ & $\mathbf{H}$ & $\mathbf{O}^{*}$ & $\mathbf{N}$ & $\mathbf{S}$ & MC & VM & FC $^{*}$ & Ash & MJ/kg \\
\hline W & 43.54 & 3.59 & 51.70 & 1.00 & 0.16 & 4.25 & 88.07 & 10.61 & 1.32 & 17.53 \\
\hline CS & 46.93 & 3.96 & 48.21 & 0.71 & 0.19 & 2.29 & 81.67 & 17.50 & 0.83 & 19.43 \\
\hline
\end{tabular}

W; Wood residual (acacia mangium), CS; Coconut shells, on difference basis ${ }^{*}$ 


\subsection{Effect of blending ratio on producer gas during W/CS co-gasification}

The variation in the producer gas composition as blending ratio varied from 0 to 100 for $\mathrm{W} / \mathrm{CS}$ and vice-versa is shown in Fig. 2. The results show that concentration of CO in producer gas was higher as compared to the other gas contents of $\mathrm{H}_{2}, \mathrm{CH}_{4}$, and $\mathrm{CO}_{2}$. The $\mathrm{CO}$ ranges between $15.2-24.0 \%$, a reason for high $\mathrm{CO}$ content was high oxygen content in biomass [26]. CO concentration showe a fluctuated decreasing trend as the CS ratio increased in blends. The co-gasification of W/CS at ratios of 60/40 and 20/80 have low concentrations of $\mathrm{CO}$ contents than the value of $\mathrm{CO}$ obtained from the gasification of pure wood and CS. The reason of low $\mathrm{CO}$ content was high moisture content of the wood feedstock for both blends, which was $15 \%$ and $14 \%$ by weight (on the wet basis) for $60 / 40$ and $20 / 80 \mathrm{~W} / \mathrm{CS}$ blends respectively. As the result of a high moisture content of wood consequently, a low pyrolysis temperature was achieved, which caused poor boudouard $\left(\mathrm{C}+\mathrm{CO}_{2} \rightarrow 2 \mathrm{CO}\right)$ and dominated water-gas shift reaction $\left(\mathrm{CO}+\mathrm{H}_{2} \mathrm{O} \leftrightarrow \mathrm{CO}_{2}+\mathrm{H}_{2}\right)$ that result in low $\mathrm{CO}$ and high $\mathrm{H}_{2}$ and $\mathrm{CO}_{2}$ of producer gas. However, a blend of 40/60 has a high concentration of $\mathrm{CO}$ content, which was $11 \%$ higher than wood residual and CS gasification results. The cogasification of 40/60 blend of W/CS has a high concentration of $\mathrm{CO}$ and low $\mathrm{CO}_{2}$, which implies a strong dominance of boudouard reaction.

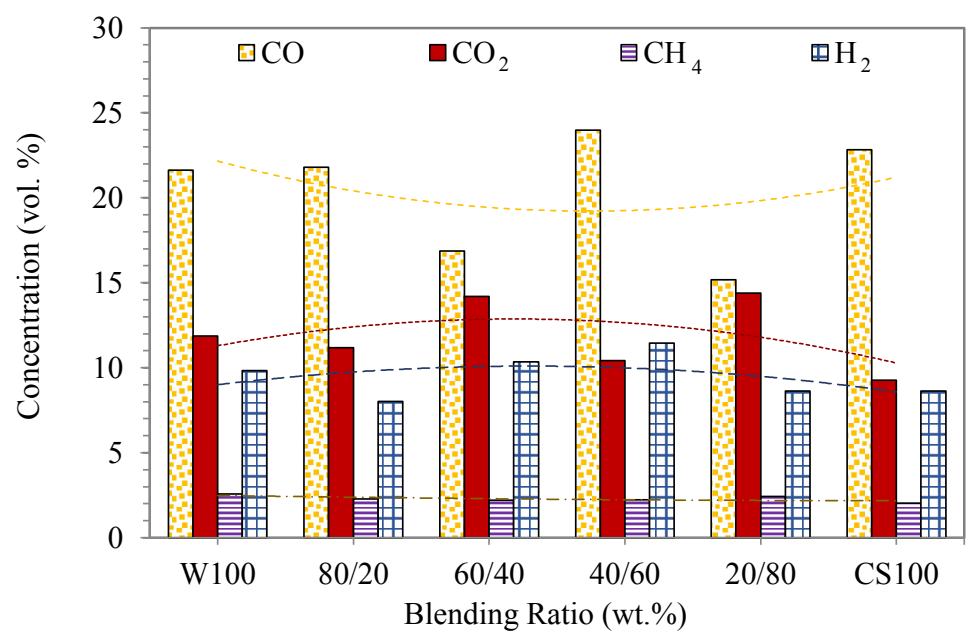

Fig. 2. Variation of producer gas composition at different W/CS blending ratios.

In producer gas, $\mathrm{H}_{2}$ is the main constituent of combustible gases, it varies from 8.01 to 11.46 vol.\% during the co-gasification of W/CS blends. As shown in Fig. 2, $\mathrm{H}_{2}$ concentration in producer gas has increasing trend for co-gasification of 80/20, 60/40 and 40/60 W/CS blends as compared to the gasification results of pure CS. On the other hand, a slight decrease was observed in $\mathrm{H}_{2}$ during co-gasification of $20 / 80 \mathrm{~W} / \mathrm{CS}$ blend as compared to gasification of $100 \%$ CS. A high concentration of $\mathrm{H}_{2}$ was due to high hydrogen content of raw wood residual and CS blends itself, which were $3.66 \%, 3.74 \%$, and $3.81 \%$ by weight in $80 / 20$, $60 / 40$ and $40 / 60$ blending ratios, respectively. The high $\mathrm{H}_{2}$ content 11.30 vol. $\%$ obtained from co-gasification of W/CS at a ratio of $40 / 60$, which is $33 \%$ higher as compared to the gasification $100 \% \mathrm{CS}$. At low moisture content $(5 \%)$ of the blend, a fast pyrolysis was observed at the comparative high oxidation and pyrolysis zone temperature of $614^{\circ} \mathrm{C}$ and $426^{\circ} \mathrm{C}$, respectively. The splashes of pyrolysis oil come out from the flare, the initial heat of combustion zone was utilized in pyrolysis zone that causes fast pyrolysis.

The $\mathrm{CO}_{2}$ concentration varied from 10.41 to 14.39 vol.\% during the co-gasification of $\mathrm{W} / \mathrm{CS}$. The $\mathrm{CO}_{2}$ and $\mathrm{CO}$ were increasing and decreasing vice versa for W/CS blends as 
clearly shown in Fig. 2. The W/CS blends at ratios of $60 / 40$ and $20 / 80$ have high $\mathrm{CO}_{2}$ contents and low CO contents as compared to gasification results of $100 \%$ wood residual and CS as mentioned before. On the contrary, 40/60 blend of W/CS has low $\mathrm{CO}_{2}$ value and high $\mathrm{CO}$ contents, which was due to high oxidation zone temperature causing the consumption of $\mathrm{CO}_{2}$ via boudouard reaction $\left(\mathrm{C}+\mathrm{CO}_{2} \rightarrow 2 \mathrm{CO}\right)$, thereby increasing the yield of $\mathrm{CO}$ in producer gas.

Producer gas has low $\mathrm{CH}_{4}$ values in most of the literature as during the co-gasification of hardwood and glycerol gasification [27]. In the present co-gasification study of W/CS blends, the $\mathrm{CH}_{4}$ concentration varied between 2.04 to 2.57 vol.\%. There was no significant effect of blending ratio on $\mathrm{CH}_{4}$ concentration. The almost similarly values of $\mathrm{CH}_{4}$ were obtained from all co-gasification experiments. Overall, 40/60 W/CS blend has a good producer gas composition among other blends. It has high $\mathrm{H}_{2}$ and $\mathrm{CO}$ contents, low $\mathrm{CO}_{2}$, and moderate value of $\mathrm{CH}_{4}$ contents. In the present study, the $\mathrm{CO}_{2}$ proportion in producer gas was noted as lower than the literature [28]. The overall process shows that add of CS in wood residual improved the gas composition and both feedstocks can be used as a substitute for each other. Furthermore, the co-gasification process has more flexibility over the utilization of feedstock.

\section{Conclusions}

The co-gasification of W/CS at various blends ratios successfully carried out in downdraft gasifier without a change in gasifier geometry. CS feedstock can be used as a substitute for wood residual in blend form in the co-gasification process. The blending ratio may vary depending on the supply of biomass materials or the desired quality of producer gas. All gaseous components of producer gas improved as the proportion of CS increased in blend up to $60 \%$, however, $\mathrm{CO}$ have a contrary trend.

The authors would like to thank and acknowledge the Universiti Teknologi PETRONAS, Malaysia, for financial and technical support for this work.

\section{References}

1. 1. F. Pinto, R. Andre, H. Lopes, Diogo Neves, F. Varela, J. Santos, and M. Miranda, Chem. Eng. Trans. 43, 2227-2232 (2015)

2. S. M. Shafie, T. M. I. Mahlia, H. H. Masjuki, and A. Ahmad-Yazid, Renew. Sust. Energ. Rev. 16, 5879-5889 (2012)

3. H. W. Kong, Fort. Res. Inst. Malaysia (2000)

4. H. C. Ong, T. M. I. Mahlia, and H. H. Masjuki, Renew. Sust. Energ. Rev. 15, 639-647 (2011)

5. S. M. Shafie, T. M. I. Mahlia, H. H. Masjuki, and A. Andriyana, Renew. Sust. Energ. Rev. 15, 4370-4377 (2011)

6. S. A. Sulaiman, M. Inayat, H. Basri, F. M. Guangul, and S. M. Atnaw, JMES. 10, 21762186 (2016)

7. M. Inayat, S. A. Sulaiman, A. Abd Jamil, F. M. Guangul, and S. M. Atnaw, ICGSCE 2014. Springer Singapore, 203-210 (2015).

8. M. Inayat, S. A. Sulaiman, A. Kumar, and F. M. Guangul, JMES. 10, 2187-2199 (2016)

9. S. Link, S. Arvelakis, A. Paist, T. Liliedahl, and C. Rosén, Renew. Energ. 115, 1-5 (2018)

10. S. A. Sulaiman, R. Roslan, M. Inayat, and M. Y. Naz, J. Energ. Inst. 91, 779-785 (2018) 
11. Y. Zhu, P. Piotrowska, P. J. van Eyk, D. Boström, X. Wu, C. Boman, M. Broström, J. Zhang, C. W. Kwong, D. Wang, A. J. Cole, R. de Nys, F. G. Gentili, and P. J. Ashman, Energy Fuels, 30, 1800-1809 (2016)

12. V. C. J. Singh, and S. J. Sekhar, Appl. Therm. Eng. 97, 22-27 (2016)

13. M. Kaewpanha, G. Guan, X. Hao, Z. Wang, Y. Kasai, K. Kusakabe, and A. Abudula, Fuel Process. Technol. 120, 106-112 (2014)

14. F. Pinto, R. N. Andre, D. Neves, F. Varela, J. Santos, M. Miranda, and J. Gominho, MTEE 2015, Florida, USA. Brown Walker Pass, 2015, 7-11.

15. B. Buragohain, P. Mahanta, and V. S. Moholkar, Int. J. Energ. Environ. 2, 551-578 (2011)

16. L. He, K. Geffers, and M. Gohla, J. Agric. Sci. Technol. 2, 1109 (2012)

17. S. Kaewluan, and S. Pipatmanomai, Fuel Process. Technol. 92, 671-677 (2011)

18. M. Inayat, S. A. Sulaiman, and J. C. Kurnia, MATEC Web Conf., 131, 03015 (2017)

19. M. Inayat, S. A. Sulaiman, and K. Sanaullah, 4th IET CEAT, 1-7 (2016)

20. P. McKendry, Bioresour. Technol. 83, 55-63 (2002)

21. E871-82, Standard Test Method for Moisture Analysis of Particulate Wood Fuels, ed. Pennsylvania, USA, ASTM International, (2006)

22. E1755-01 Standard Method for the Determination of Ash in Biomass, ed. Philadelphia, USA, ASTM International, (2007)

23. D3176-09 Standard Practice for Ultimate Analysis of Coal and Coke, ed. West Conshohocken, ASTM International, (2009)

24. D4809-00, Standard Test Method for Heat of Combustion of Liquid Hydrocarbon Fuels by Bomb Calorimeter (Precision Method), ed. Pennsylvania, USA, ASTM International, (2013)

25. F. M. Guangul, S. A. Sulaiman, and A. Ramli, Bioresour. Technol. 126, 224-232 (2012)

26. E. L. Taba, M. F. Irfan, W. M. A. Wan Daud, and M. H. Chakrabarti, Biomass Bioenergy, 57, 249-263 (2013)

27. L. Wei, L. O. Pordesimo, A. Haryanto, and J. Wooten, Bioresour. Technol. 102, 62666272 (2011)

28. J. J. Hernandez, G. A. Almansa, and C. Serrano, Energy fuels, 24, 2479-2488 (2010) 